\title{
The Impact of the Implementation of Capability Maturity Model Integration on User Satisfaction: Case Study on Software Companies in Jordan
}

\author{
Mohammad Issam Khalil Abu-Baker' ${ }^{1}$ Mohammad Khair Saleem Abu-Zaid ${ }^{2}$, Hamad \\ Alsawalqah ${ }^{3}$, Yazan Al-Shamayleh ${ }^{3 *}$, Bashar Al-Shboul ${ }^{3}$ \\ 1 Eskadenia Software, Amman, Jordan. \\ 2 Faulty of Graduate Studies, Al-Balqa' Applied University, Al-Salt, Jordan. \\ ${ }^{3}$ King Abdullah II School of Information Technology, The University of Jordan, Amman, Jordan. \\ * Corresponding author. Tel.: +962796189480; email: yalshamaileh@gmail.com \\ Manuscript submitted February 15, 2019; accepted April 12, 2019. \\ doi: 10.17706/jsw.14.7.293-311
}

\begin{abstract}
The Capability Maturity Model Integration, as part of the software process improvement, has been receiving attention due to the belief of its relevance to the customer satisfaction factor. This research aims at offering software companies in Jordan an overview of Capability Maturity Model Integration methodology and its benefits for the software industry. To study the impact of its implementation on customer satisfaction, through the quality of the software, and provide recommendations on increasing the awareness of Capability Maturity Model Integration, a quantitative study is designed. Four perspectives related to Capability Maturity Model Integration have been studied: the effect of its implementation on customer satisfaction as well as software quality, the effect of software quality on customer satisfaction, and the effect of its implementation on customer satisfaction through the software quality. The results concluded that there is a direct effect of implementing Capability Maturity Model Integration on customer satisfaction and software quality. It also shows that higher software quality positively affects customer satisfaction; i.e. software quality plays a mediation role between the effect of Capability Maturity Model Integration implementation and the customer satisfaction.
\end{abstract}

Key words: Capability maturity model integrated, customer satisfaction, software quality.

\section{Introduction}

Software quality has received much attention recently in both academia and industry. This is due to the role of software in modern-day business and modern-day living. The issue of software quality has been brought into sharp focus because of the disappointing performance of few "high profile" software projects and high rate of software projects failure. A recent report showed that in 2016 and 2017, organizations spent $31 \%$ of their budget to tackle quality issues in comparison with the previous years [1]. The study of the Standish Group [2] showed that $31.1 \%$ of all information technology development projects are cancelled, $52.7 \%$ are completed only way over budget and/or behind schedule, and only $16.2 \%$ deemed a success (are completed on budget and schedule). The search for solutions to improve software quality has continued for many years and software organizations are now realizing that one of their fundamental problems is the inability to effectively manage the software process [3], [4]. Software organizations also realize that effectiveness of their processes is as crucial as being able to cope with the rapid changes in the market [1]. In 
order to address the effective management of software process, different Software Process Improvement (SPI) standards have been developed. SPI has been a long-standing approach intended to help organizations develop higher-quality software more efficiently, in addition to creating strategic advantages with respect to their competitors ensuring quality [5]. SPI standards attempt to solve issues resulted from software processes and trying to find the best solutions during the usual cycles such as planning and development. Adding to that, SPI targets management and organizational problems [8]. A study to compare between the impact of adopting SPI in Canadian and Caribbean firms has been conducted. The main advantage in both of the developed and developing firms is improving software quality [9]. This study is consistent with other previous studies which stresses that SPI improves software quality, staff productivity, enhances customer satisfaction and reduces cost and time.

Capability Maturity Model Integration (CMMI) is one of the SPI frameworks that focuses on processes to achieve quality software [10], [11]. CMMI is defined as a process improvement maturity model, administered and marketed by Carnegie Mellon University (CMU), for the development of products and services. Reference [12] illustrated the reasons behind implementing CMMI. CMMI are used for process improvement and appraisals. For process improvement, CMMI targets 25 process areas. It concentrates on developing the solutions, improving the process of purchasing products and enhancing the delivery of services. In addition to the improvement of the process, CMMI is also utilized to assess the performance of the organization. In addition, the main objective of this model is to reduce the cost that results from implementing various improvements in the organization processes by eliminating inconsistencies and establishing guidelines in order to assist the organization at different stages of a software project [13]. According to the CMMI Institute, there are over 5,000 organizations and businesses that use CMMI models. From over 101 countries,11 governments (U.S., Russia, China, Australia, Germany, Italy, India, Turkey, Pakistan, Egypt, and Chile) invest in CMMI to support economic development in their countries. To support governments and organizations, CMMI models have been translated into 10 languages. In 2017, CMMI Institute reported that more than 2,237 organizations earned CMMI appraisal rating in 2016 all over the world which equals a 16\% increase regarding the number of completed appraisals ${ }^{1}$. Implementing CMMI mandates that companies go through a number of procedures and diagnostic assessments. Acquiring the CMMI certificate is an advantage to each company as it improves quality, productivity, schedule and budget predictability, increases customer satisfaction, return on investment and innovation and raises the ability to manage risks. In addition, [14] suggests that "an organization cannot be certified in CMMI; instead, an organization is appraised. Depending on the type of appraisal, the organization can be awarded a maturity level rating (1-5) or a capability level achievement profile". When an organization arrives level 5 , it means that this organization arrives the optimal level which is the highest level of commitment to improve its processes.

Jordan has traditionally been a regional leader in developing, adopting and utilizing information and communication technology (ICT). In recent decades, Jordan's lead has decreased over regional economies. The sector needs to identify ways and means to identify and consolidate such experience to develop sustainable competitive advantage. Unfortunately, many Jordanian companies do not apply international quality standards (i.e., CMMI) in all phases of software life cycle [15]. One of the empirical studies investigated the use of CMMI in web development companies and found that the majority of the respondents (81\%) have not previously participated in any SPI activities (training, implementation and practicing) [16]. CMMI adoption across many companies might facilitate increased cooperation among ICT companies and improve Jordan's ICT capability to develop internationally sustainable national ICT competitiveness. Moreover, in order for the local Jordanian software development industry to become more competitive on a global scale,

1 Attain appraised at capability maturity model integration (CMMI) maturity level 5. (2018, Apr 17). PR Newswire Retrieved from https://search.proquest.com/docview/2025812261?accountid=27719 
it will need to fall into line with international standards, so that local Jordanian companies seeking international contracts will be able to meet the CMMI level specified by international companies. Many Jordanian companies like Primus, STS, and ESKADENIA are CMMI certified and they implement it successfully. These companies are believed to be the leaders in the IT local Jordanian market in software industry. However, many other companies are not certified, but they are convinced that setting up well-controlled processes will help in increasing the quality of their final products and hence increasing the customer satisfaction.

Through our practical experience in the quality assurance field in the past seven years in different IT companies in Jordan, we have noticed that although these companies are following different sets of processes in assuring the quality, created, planned, and deployed by these companies according to their goals, those sets were no clear and standardized, especially the ones recommended by international institutes which added to the software industry different quality management methodologies that assure the delivery of high quality software and increase customer satisfaction. Consequently, many Jordanian IT companies suffer from serious problems with the market such as missed commitments, late delivery to the market and last-minute crunches. Also, they internally suffer from inadequate management capabilities and quality problem. As a result, customer satisfaction of the end-user is decreased which can be seen in the too many complaints they receive. This study aims to contribute to this research domain by investigating the level of implementing CMMI principles in Jordanian IT companies, the effect of implementing CMMI principles on customer satisfaction, and whether there is an indirect effect of implementing CMMI principles on customer satisfaction through software quality.

The findings and recommendations of this research have significant implications for managers, software vendors and researchers which will help in increasing the awareness of CMMI concepts and benefits for the IT companies' owners and top management in Jordan. In addition, the current study gives empirical analysis of the effect of implementing CMMI approach on the quality of the services and products provided by the software companies in Jordan and on customer satisfaction.

The remainder of this paper is organized as follows: Section 2 presents the research work related to the solution approach. Section 3 presents the research methodology. Section 4 presents the results of the study. Section 5 presents a discussion of research findings and managerial implications. Section 6 concludes the paper with a summary and a set of recommendations for the Jordanian IT companies to increase the satisfaction of their customers.

\section{Related Work}

Contributions Software engineering researchers always seek better ways to develop and evaluate software [6]. Many researchers identified that the importance of CMMI can be through improving competitiveness and quality. Several researchers studied the impact of software process improvement on organizations performance to enable SPI program managers to concentrate more on "high perceived value" practices [17][19]. Reference [20] studied the impact of implementing a software project to CMMI level 5 certified organization on the overall software productivity. The results prove that implementing CMMI level 5 has a notable effect. It increases the code creation productivity up to $27 \%$. Adding to that, the results show that during the code phase, the tools that utilized were effective and made a difference in improving the productivity as well as increasing the benefit of the cost. Reference [21] qualitatively studied the benefits of the CMMI and how to assess them. Furthermore, another study conducted lately in 2016 shows the importance of maturity models in general. It also analyzes the use of CMMI in different organizations and how to benefit from it [22]. References [23] and [24] provided detailed explanations and illustrations about the model while [25] studied CMMI and highlighted the vast benefits of CMMI implementations on the quality of the software. Reference [26] made a comparison between Six Sigma and CMMI and clarified that CMMI 
implementation is more beneficial to software industry as it positively affects the software quality and customer satisfaction. He also suggested a model combining some of the ideas from both models.

Reference [27] recommended the implementation of CMMI model for software companies for its great effect on reducing defects. While [28] concluded that quality of services is greatly enhanced when implementing CMMI especially the areas that enhance the processes of providing services to customers. Reference [29] studied the impact of the CMM on certain critical factors in information systems' implementation strategy, software quality and software project performance. They found that CMM levels do associate with Information System implementation strategies and higher CMM levels relate to higher software quality and project performance. Reference [30] found that higher quality management intensity led to higher end-user satisfaction and lower quality management intensity led to lower end-user satisfaction. Reference [5] stated that the reasons for adopting CMM-based SPI approaches in organizations are usually related to product quality and project performance, and less commonly, to process. Organizations reported customer reasons infrequently and employee reasons very rarely. CMMI is also used to assess organizational maturity which proves its effectiveness. The results confirmed that CMMI is suitable for assessing organizational maturity [31]. Another study stated that software companies can benefit from CMMI by hiring developers with the highest level of process maturity in order to produce software with higher quality; this state came from the fact that the use of high levels of process maturity will definitely reduce defects, achieve stakeholder satisfaction, improve and maintain efforts and enhance software management [32]. A systematic review has been conducted to examine the influence of using both of CMMI and agile software development in the organizations. The results revealed that the benefits are related to the organization and to the development of the processes as well [33].

As SPI projects are risky and may easily fail, [34] proposed a new methodology to make projects more successful. This methodology called "process Increments" and by using it, CMMI-based projects were improved and gained more success. They finally stated that The SPI results have dramatically improved. As a result, we can conclude that CMMI is flexible and can be improved to gain successful results. Another work done by [35] supports the idea of combining CMMI with other methodologies in order to gain more success. In this work, the researchers highlighted the fact that risk assessment is crucial to the increase of software development project success. Thus, they presented an automated risk assessment framework using CMMI and risk taxonomy as a guidance to develop a risk assessment model.

Using a national quality survey from 482 companies in Sweden, the analysis of [36] showed that for product organizations, internal quality practices which influence customer satisfaction and business results primarily through an organization's customer orientation. For service organizations, both customer and process orientation impact customers directly, and employee management has a direct impact on business results. The research also supports the claim that organizations with a quality foundation are in a better position to adopt a customer orientation. Reference [37] showed that cost benefits for implementing CMMI are substantial and worthwhile. Implementing CMMI provides any organization with benefits such as making them more competitive in the market place. Implementing CMMI reduces the number of defects in the product by 39 percent. The CMMI improvements increase the employee moral by preventing crises. CMMI has proved its effectiveness in examining its impact of the return of investment. The benefits can be summarized as reducing the product cost, finding and fixing the defects, reducing the time needed to complete the projects, improving the quality, and an overall useful return of investment [38]. Reference [39] aimed to demonstrate the impact of using the CMMI approach on the quality and the end-user satisfaction. While still limited, the results presented in this study provide credible quantitative evidence that CMMI based process improvement can result in better project performance and higher quality products. Parzinger and Nath [40] found that measures of software quality are affected by the change in the customer satisfaction and 
the CMM level. Adding to its success in targeting the issues of time and cost, CMMI has an impact on quality. Reference [41] studied the impact of CMMI implementation on quality in the Russian engineering companies. The findings show that there was a remarkable improving in the field of quality management. The number of defects have decreased by 62,5\%. Implementing SPI standards become a universal requirement. Reference [42] stated that the Egyptian software organizations attempt to improve the quality of their process and CMMI is the preferred one for those organizations.

CMMI can be combined with other methodologies in order to achieve a certain business goal [43]. Lukasiewicz and Miler's study [43] stated that combining CMMI with Scrum methodology will improve both agility and discipline of software development. They verified their work by applying it into two IT companies and they concluded that their work is capable for supporting organizations with different levels of maturity and agility. According to CMMI Institute [44], 70\% of the organizations that implement CMMI use agile. CMMI solves issues and problems that agile organizations have such as performance. Reference [45] stated that the implementation of CMMI is hard for small organizations because of the high costs. As a solution, a combination of CMMI and agile methods have been suggested. It has been reported that the combination has a great result and several benefits for small organization.

Reference [46] investigated the extent of adapting the total quality procedures in the Jordanian software companies to find the main problems behind not adapting total quality standards. They have found a strong positive relationship between the application of the quality management practices and the quality of the produced software. Accordingly, they recommended the application of the quality management procedures in order to increase the quality of software produced by the Jordanian companies. Samman [47] aimed to develop a model for improving the business performance of the Jordanian organizations by the integration of the TQM to process development and re-engineering. Although these organizations are not specialized in producing software, but Samman's study is important as he investigated the possible integration between TQM and processes development regardless of the industry of the interviewed organizations, which is implied by the development of the CMMI model to serve the quality management of the software industry. Authors in [15] highlighted the main success factors of the Jordanian software companies in order to be able to compete in the rapidly changing market. The study concluded that it is necessary for Jordanian companies to apply the international standards to improve software industry in Jordan and get the desired position in the market. Reference [48] developed a model for small Palestinian software development firms to help them in making a self-evaluation for their software development process and find areas for improvements. The author identified that Process Improvement Areas were considered important and least implemented inside small software firms. This result justified the need for process improvement framework that is tailored for small software firms in Palestine. The conclusion was that all of the key Process Areas are considered important for small software firms to succeed in delivering highly quality software products.

Although there is a fair number of researches that have studied different quality management approaches in Jordan, very few of them discussed CMMI and its effects on different dimensions in the Jordanian software industry and market. Moreover, the effect of the implementation of CMMI in approach on customer satisfaction is still not addressed in these studies. Hence, this study can be very helpful for the post researchers who would like to conduct further research in this domain and especially if they want to consider the local Jordanian software industry environment. This study will guide them through the status of the local Jordanian market and its perspective of CMMI and the awareness of its effect on the local market.

\section{Research Methodology}

The study model was built based on both James Settleourre study [48], which depicts an indirect effect of CMMI implementation on customer satisfaction through software quality, and Goldenson and Gibson study 
[49] that depicts a direct effect of CMMI implementation on the customer satisfaction. The study model consists of Independent variables (i.e. Quality Management, Strategy Management, Work Processes and Procedures, Data Gathering and Analysis, Focus on Customers, People Management, and Top Management and Leadership), Moderating variable (i.e. Quality of the software), and Dependent variable (i.e. Customer Satisfaction).

Throughout this research, several hypotheses are suggested and will be tested, specifically:

- H1: There is no direct significant effect of CMMI principles on customer Satisfaction.

- H2: There is no direct significant effect of quality of the software on customer satisfaction.

- H3: There is no direct significant effect of the implementation of CMMI on the software quality.

- H4: The software quality mediates significantly the impact of CMMI principles on the customer satisfaction.

To test and validate our hypotheses, the population for this study is a group of software companies in Jordan. According to Int@j2 $\mathrm{j}^{2}$, there are around 60 operating Jordanian software houses. A survey has been designed and distributed to the managers (i.e. people in leading positions with sufficient knowledge of quality management best practices while having knowledge on customer satisfaction levels of their software products). Some descriptive statistics can be found in Table 1 and Table 2.

The survey consists of four sections: demographical questions (i.e. to gather information about the survey respondents and their companies), implementation areas of CMMI (i.e. covering the seven independent variables), quality of the produced software (i.e. the degree of reliability, usability, low cost, and responsiveness), and customer satisfaction (i.e. to measure the acceptance of software by its users). Survey questions were peer-reviewed by several "expert" judges ${ }^{3}$ to ensure their validity. Cronbach's alpha reliability coefficients were calculated for the variables of the study. For the survey tool to be reliable, Alpha values should be higher than 0.60 , which applies to all variables as shown in Table 3 . The analysis of the data has been carried out using a set of statistical methods (i.e. descriptive statistics, simple regression, multiple regressions, and hierarchical multiple regression). For specifying the degree of the estimation through the values of the resulted means, they were encoded to the Likert 5-points scale as shown in Table 4.

Table 1. Descriptive Statistics of Survey Respondents

\begin{tabular}{lcc}
\hline \hline Gender & Frequency & Percentage \\
\hline Male & 128 & $84 \%$ \\
Female & 24 & $16 \%$ \\
\hline Experience (Years) & Frequency & Percentage \\
\hline Less than 5 & 2 & $1 \%$ \\
$5-9$ & 102 & $68 \%$ \\
$10-14$ & 42 & $28 \%$ \\
$15-19$ & 4 & $2 \%$ \\
More than 19 & 2 & $1 \%$ \\
\hline Age & Frequency & Percentage \\
\hline Less than 30 & 66 & $43 \%$ \\
$30-39$ & 84 & $55 \%$ \\
$40-49$ & 2 & $2 \%$ \\
Above 50 & 0 & $0 \%$ \\
\hline
\end{tabular}

2 The Information and Communication Technology Association of Jordan (int@j):http://www.intaj.net/

3 Six PhD holders, with academic positions were asked to comment on the evaluation measures. Common majority notes were considered for applying adjustments 


\begin{tabular}{lcc}
\hline Education & Frequency & Percentage \\
\hline Bachelor Degree & 120 & $78 \%$ \\
Masters & 30 & $20 \%$ \\
Diploma & 2 & $2 \%$ \\
Other & 0 & 0 \\
\hline \hline
\end{tabular}

Table 2. Descriptive Statistics on Surveyed Companies

\begin{tabular}{lc}
\hline \hline Year of Establishment & Frequency \\
\hline Before 1990 & 6 \\
$1990-1999$ & 11 \\
$2000-2009$ & 25 \\
After 2009 & 1 \\
\hline Number of Employees & Frequency \\
\hline Less than 50 & 11 \\
$50-149$ & 18 \\
$150-249$ & 2 \\
$250-349$ & 1 \\
$350-449$ & 2 \\
More than 500 & 2 \\
\hline Company Have Branches ? & Frequency \\
\hline Yes & 102 \\
No & 50 \\
\hline \hline
\end{tabular}

Table 3. Cronbach's Alpha

\begin{tabular}{lc}
\hline \hline Variables & Cronbach's Alpha \\
\hline Quality Management in the Organization & 0.920 \\
Strategic Management and Planning & 0.919 \\
Work Processes and Procedures & 0.936 \\
Focusing on Customers & 0.764 \\
Data Collecting and Analysis & 0.856 \\
People Management & 0.867 \\
Top Management and Leadership & 0.772 \\
Customer satisfaction & 0.951 \\
\hline Software quality & 0.797 \\
\hline \hline
\end{tabular}

Table 4. Distribution of the Means Scores on 5-Point Likert Scale

\begin{tabular}{cc}
\hline \hline Mean Value & Estimation Degree \\
\hline $1.00-1.80$ & Very Low \\
$1.81-2.60$ & Low \\
$2.61-3.40$ & Average \\
$3.41-4.20$ & High \\
$4.21-5.00$ & Very High \\
\hline \hline
\end{tabular}

\section{Results}

\subsection{Means and Standard Deviations of Study Variables}


Summary of the descriptive statistics for the set of question categories designated for this study is shown in Figure (1). The detailed questions and their descriptive statistics are shown in the table in appendix A. From the figure, it can be noticed that the means and the standard deviations of the question categories vary slightly; therefore, a deeper look at individual questions for each category is required. For example, Among the quality management practices in the organizations question set (i.e. Q1 through Q14), Q4 and Q13 have got the lowest results. The answers to Q4 show an average tendency for companies to implement quality management practices; however, there is no clear definition of the percentage of accepted errors. This can be due to the difficulty to specify a precise percentage of errors in practice. The ones who agreed on this question are from the organizations that are ranked at level 4 and higher on CMMI. As for statistics of Q13, it can be noticed that few IT professionals are aware of CMMI model, which coincides with [36]. On the other hand, Q10 got the highest mean indicating that most surveyed companies do testing before implementing their products to their end-users, regardless whether the processes of this testing phase are effective or not. From our perspective, most IT companies in Jordan seem to perform testing prior to the implementation phase as indicated in the software development life cycle where testing has to be done before the implementation.

It is also shown that at the strategic management \& planning, Q22 has got the lowest mean $(M=2.85)$, which is consistent with answers to Q4; since not many companies define a specific and accepted ratio of errors, therefore, they won't be aware of this ratio in the first place. On the other hand, Q15 got the highest mean $(M=3.91)$; companies strive for developing the quality. This is because most of the surveyed IT companies in Jordan are established by unexperienced young entrepreneurs in terms of software process improvement models. Questions 27 through 37, the work processes \& procedures questions set, show an average implementation level of defined and documented work procedures and processes. This can be attributed to the variety of surveyed company sizes. It is common that small companies' procedures can be semi-defined or undefined, while big companies have clear goals and objectives at the operative level, based on which processes and procures will be clearly set. For instance, Q35 got the lowest means ( $M=2.96)$, in harmony with Q13 suggesting that few companies in Jordan follow processes and procedures defined by the CMMI approach. In addition, the second/third lowest means (i.e. Q36 and Q37) demonstrate that few IT companies set proactive action plans to anticipate errors, in order to maintain an accepted ratio of errors, or preventing them. This can be attributed to the same reason, where a quality management model that sets a proactive action plan (e.g. CMMI, Six Sigma, among others) is not adopted. Consistently, most answerers to Q32 suggests learning from past experiences $(\mathrm{M}=3.63)$. This is because, regardless of the final software quality, companies in Jordan learn from customers' feedback. This, also, comes in harmony with Q40, where most IT companies in Jordan focus on measuring customer satisfaction. This can be attributed to the high competitiveness of the Jordanian IT market where a company survival is highly correlated to maintaining an accepted level of customer satisfaction.

Further, questions 41 through 44 measure whether IT companies in Jordan use specialized systems for data gathering and analysis. Results show that, generally, top-level managers are aware of the benefits of such systems on producing high quality products; however, it is shown that in average less number of managers know how to effectively use them. Questions 45 to 48 discuss the levels of People Management in the surveyed companies. Mainly, questions 46 and 47 discuss employee satisfaction levels concerned with financial issues. For instance, Q46 shows that IT personnel communicate many issues they encounter in their work to upper management (mean=3.61), especially when it comes to improving processes due to the encouragement of communication and information sharing, resulting in many cases of high positions offer as a compensation of inability of paying them high salaries. On the other hand, Q47 show that job satisfaction is a major concern given the rapidly changing IT environment, resulting on a behaviour of seeking better job opportunities where employees are better paid, and a feeling of depreciation and underpaid. Questions 49, 50, and 51 
measure the top management \& leadership. According to analysis results, high level of leadership in IT companies in Jordan is represented by the high support of top management to the employees (i.e. Q50, Q46). It was noticeable that many answers were submitted by young employees who were tempted by top management offers to participate and develop, aiming at achieving strategic goals of the companies. Questions 52, 57, and 63 are meant to measure the satisfaction of the end-users. Analysis results show that end-users are highly satisfied with the software produced. This can be explained by the booming need to use information systems in almost all life aspects in Jordan, which makes the market finds almost any computer system helpful. The results do not show high satisfaction due to the market realizing that there are Softwares better than others due to high competition in the IT industry. Some questions related to the software quality are shown in the Table 5. Questions show average level of quality in the produced software. This can be attributed to many reasons, the most important one is the lack of efficient and effective systems that quantitatively measure the software quality. On the other hand, Q17 shows that a majority of IT companies search for ways to reduce the costs of the errors and defects, regardless of the effectiveness of their ways.

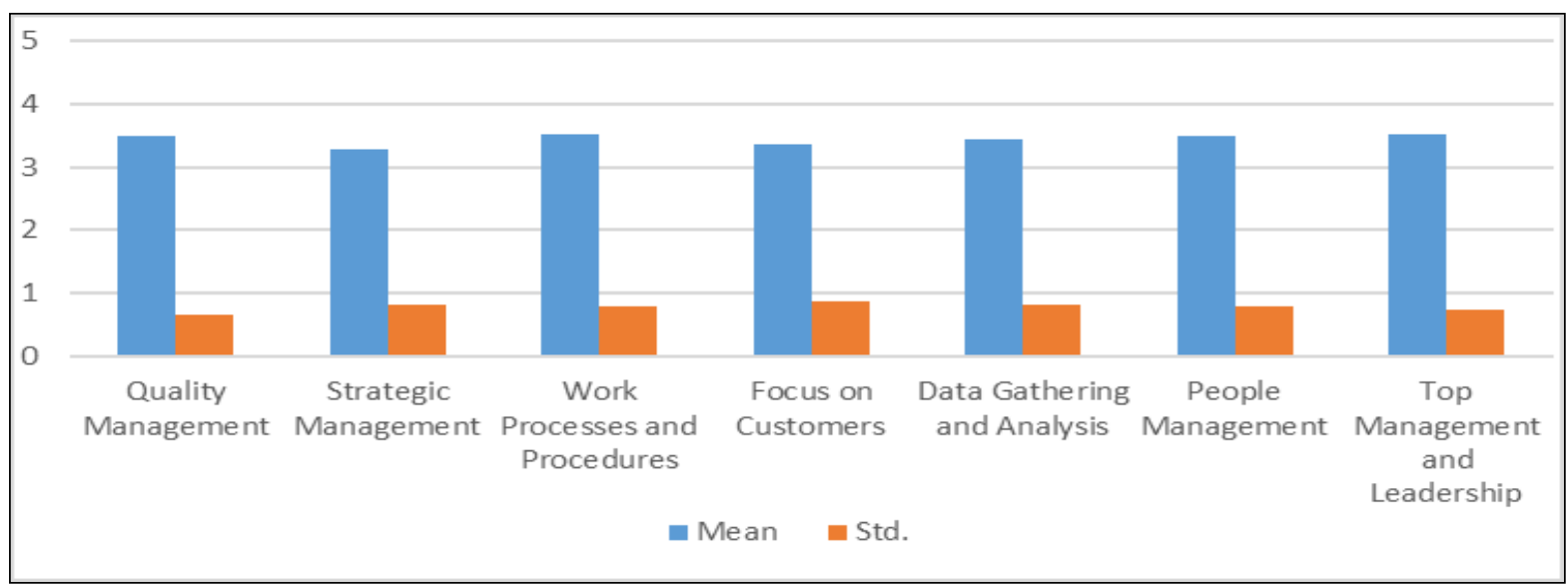

Fig. 1. Summary of the descriptive statistics for the set of question categories designated for this study.

\subsection{Hypotheses Testing}

\subsubsection{The effect of CMMI principles on customer satisfaction}

Table 5. Descriptive Statistics of the Software Quality

\begin{tabular}{clccc}
\hline \hline No. & \multicolumn{1}{c}{ Items } & Mean & Std. Deviation & Estimation Degree \\
\hline Q5 & We are able to measure output quality accurately. & 3.22 & 1.135 & Average \\
Q17 & We continually search for ways to cut down on production errors. & 3.81 & .933 & High \\
Q28 & We employ processes to identify and correct problems as they occur. & 3.24 & 1.061 & Average \\
Q58 & Do you think the output is presented in a useful format? & 3.41 & 1.051 & Average \\
\hline Overall Mean & 3.4211 & .82561 & Average \\
\hline \hline
\end{tabular}

The results of multiple regression analysis shown in Table 6 indicate that there is a direct effect of CMMI implementation on customer satisfaction, indicating that CMMI implementation explains $66.8 \%$ of the variance in customer satisfaction. Given that $(F=41.375)$ at $(P<0.05)$, so we reject the null hypothesis and accept the alternative, which points towards that there is a direct effect of the implementation of CMMI on customer satisfaction. It can be noticed, as well, that there are two significant positive relationships with the customer satisfaction at $p<0.05$ (i.e. quality management in the organization, work processes and procedures). A less significant relationship can be found at $p<0.1$ between customer satisfaction and the top 
management and leadership. On the other hand, results indicate that strategy management and planning, focusing on customers, data collecting and analysis, people management show no significant effect on the customer satisfaction. These results come in harmony with the study of [50].

\subsubsection{The effect of software quality on customer satisfaction}

The result of simple regression demonstrates that there is a direct effect of software quality on customer satisfaction, where coefficient of determination reported score of $(0.673)$ indicating that $67.3 \%$ of the variance in customer satisfaction can be explained by the software quality at significance level of 5\%; therefore, the hypothesis is rejected, and its alternative is accepted (i.e. there is direct significantly effect of quality of the software on customer satisfaction at significance level of 5\%). The results, illustrated a strong relationship between a software quality and satisfied customers, are in agreement with the literature as in [30], [36], and [40].

\subsubsection{The effect of the CMMI implementation on the software quality}

Results reported on multiple regression (i.e. Table 7) show a direct effect of CMMI implementation on the software quality, where CMMI implementation explains $76.3 \%$ of the variance in the software quality at a significance level of 5\%; therefore, the hypothesis is rejected, showing that there is a direct effect of the implementation of CMMI on software quality. The results of the regression test indicate that there is a positive significant relationship between quality management and the work processes and procedures on the software quality. These results agree with results of [29] and [48].

Table 6. Multiple Regression Test of the Implementation of CMMI Areas and its Effect on Customer Satisfaction

\begin{tabular}{lccc}
\hline \hline CMMI principles & Beta & T value & Sig \\
\hline Quality Management in The Organization & 0.427 & $3.186^{*}$ & 0.002 \\
Strategic Management and Planning & 0.085 & 0.732 & 0.466 \\
Work Processes and Procedures & 0.268 & $2.357^{*}$ & 0.020 \\
Focusing on Customers & -0.014 & -0.188 & 0.851 \\
Data Collecting and Analysis & 0.011 & 0.117 & 0.907 \\
People Management & -0.038 & -0.542 & 0.589 \\
Top Management and Leadership & 0.133 & 1.842 & 0.068 \\
\hline R & & 0.668 & \\
F & & $41.375^{*}$ & 0.000 \\
Sig & & 2 \\
\hline \hline
\end{tabular}

Table 7. Results of Multiple Regression Test of the Implementation of CMMI Areas and Its Effect on Software Quality

\begin{tabular}{lccc}
\hline \hline CMMI principles & Beta & T value & Sig \\
\hline Quality Management in The Organization & 0.495 & $4.297^{*}$ & 0.000 \\
Strategic Management and Planning & 0.072 & 0.724 & 0.470 \\
Work Processes and Procedures & 0.383 & $3.907^{*}$ & 0.000 \\
Focusing on Customers & -0.075 & -1.137 & 0.257 \\
Data Collecting and Analysis & 0.021 & 0.262 & 0.794 \\
People Management & -0.057 & -0.950 & 0.344 \\
Top Management and Leadership & 0.038 & 0.621 & 0.536 \\
\hline R & & 0.763 & \\
F & & $67.288^{*}$ & \\
Sig & & 0.000 \\
\hline \hline
\end{tabular}


Table 8. Summary of Results: Impact of Mediated Regression

\begin{tabular}{|c|c|c|c|c|c|c|}
\hline \multirow{2}{*}{$\begin{array}{l}\text { Variable } \\
\text { CMMI principles }\end{array}$} & \multicolumn{2}{|c|}{$\begin{array}{c}\text { Customer satisfaction } \\
\text { Model } 1\end{array}$} & \multicolumn{2}{|c|}{$\begin{array}{c}\text { Software quality } \\
\text { Model } 2\end{array}$} & \multicolumn{2}{|c|}{$\begin{array}{c}\text { Customer satisfaction } \\
\text { Model } 3\end{array}$} \\
\hline & B & t.value & B & t.value & B & t.value \\
\hline Quality Management in the Organization & 0.427 & $3.186^{*}$ & 0.495 & $4.297^{*}$ & 0.211 & 1.598 \\
\hline Strategic Management and Planning & 0.085 & 0.732 & 0.072 & 0.724 & 0.054 & 0.500 \\
\hline Work Processes and Procedures & 0.268 & $2.357^{*}$ & 0.383 & $3.907^{*}$ & 0.102 & 0.917 \\
\hline Focusing on Customers & -0.014 & -0.188 & -0.075 & -1.137 & 0.018 & 0.257 \\
\hline Data Collecting and Analysis & 0.011 & 0.117 & 0.021 & 0.262 & 0.002 & 0.020 \\
\hline People Management & -0.038 & -0.542 & -0.057 & -0.950 & -0.013 & -0.196 \\
\hline Top Management and Leadership & 0.133 & 1.842 & 0.038 & 0.621 & 0.117 & 1.732 \\
\hline Software quality & & & & & 0.437 & $4.869 *$ \\
\hline $\mathrm{R}^{2}$ & \multicolumn{2}{|c|}{0.668} & \multicolumn{2}{|c|}{0.763} & \multicolumn{2}{|c|}{0.715} \\
\hline $\mathrm{F}$ & \multicolumn{2}{|c|}{41.375} & \multicolumn{2}{|c|}{$67.288^{*}$} & \multicolumn{2}{|c|}{$44.874^{*}$} \\
\hline
\end{tabular}

\subsubsection{Mediation effect of software quality between CMMI principles and customer satisfaction}

To analyze the mediating effect of software quality between CMMI and customer satisfaction, hierarchical multiple regression has been used. This experiment comes in three folds. First, to examine the relationship between independent variable and the dependent variable (i.e. Model 1). The results show that Quality Management in the Organization and Work Processes and Procedures relate significantly to customer satisfaction. The second fold is to examine the effect of the independent variables (i.e. CMMI principles) on the mediator (i.e. software quality). The results (i.e. Model 2) indicate that Quality Management in the Organization and Work Processes and Procedures have positive and significant effects on software quality. Finally, on the third fold (i.e. Model 3), the mediator is included to examine whether it reduces the effects of the antecedents to non-significance. As results show in Table 8, the coefficients for software quality are positive and significant, indicating the direct effect of software quality on customer satisfaction. Further, software quality significantly reduces the effects of CMMI principles on the dependent variable, all of them to non-significant, and attenuates the relationships between CMMI principles and customer satisfaction. Thus, software quality plays a mediating role between CMMI principles and customer satisfaction, supporting the mediation effect in $\mathrm{H} 4$.

\section{Discussions}

In terms of Quality Management, Jordanian IT companies do testing on software before being sold to the customers. Also, there is a high level of awareness about the importance of the quality procedures among the people at the management level, but not many of them are aware enough of CMMI approach and its benefits on enhancing the software quality. Main weakness point found as per the results is that many Jordanian IT companies do not specify an accepted ratio of errors. This leads to make people in the operational level not aware of whether the errors are accepted or not, which leads to produce low quality software. In addition, Jordanian IT companies continually look to improve the quality of the software they produce, and they bear in mind that they need to set strategies towards a continuous improvement in the quality of their products and enhance the customer satisfaction. Also, these companies are aware of the high costs generated by defects if found by their customers.

Further, the results reveal that Jordanian IT companies are relying on past experiences to overcome the issues they encounter in building software. This is a strong indication that these companies highly depend on feedback from customers to measure their acceptance of the software. Also, there is high effort done by top 
management in IT companies in Jordan towards encouraging their subordinates to develop in their jobs. Top management is aware of the benefits of keeping skillful resources in their companies rather than losing them for their competitors. But they tend to not to share their subordinates in setting strategic plans. Furthermore, IT companies in Jordan appear to be taking care of their employees. Though this is a general perception, but the managers who answered this section show that there is no high job satisfaction.

In addition, IT companies in Jordan continuously keep in touch with their customers to measure their satisfaction towards the software that they produce. This is a good indication that the Jordanian IT companies tend to focus on their customers to stay competitive in the market. The results show moderate tendency towards having the customers participate in setting the accepted ratio of errors. This tendency may have drawbacks in the focusing on the customers to know their level of satisfaction. Further, IT companies in Jordan use specialized systems to measure the customer satisfaction. But, the results show that many IT companies in Jordan do not use specialized systems to help them measure their position in the market, and to know their competition status.

Measuring the CMMI effect on customer satisfaction shows that IT companies in Jordan deliver an average software quality according to the following aspects: reliability, cost efficiency, usability, and responsiveness. In terms of reliability, companies implement an average level of procedures that assure reliability of software, resulting in moderate software reliability. As per cost efficiency, companies extensively search for ways to reduce costs in software caused by additional quality assurance and maintenance costs for defected products. The results show that software produced by IT companies in Jordan lack major defects that would generate such an additional cost. It is also observable that software products offered by Jordanian companies, generally, have an average usability and responsiveness, leading to a lower software quality. Results show that companies implementing quality management and work processes while developing their software results in higher software quality, which consequently enhance the customer satisfaction. Customers satisfied by the functionalities implemented for their software; however, they are moderately satisfied with the accuracy of the systems, as well as, their output representations (i.e. formatting) generated by the systems. It was observed that there is a direct effect of CMMI implementation on customer satisfaction, where the effect emerges through the implementation of Quality Management and Work Procedures and Processes areas. But there was no direct effect from the implementation of Strategic Management and Planning, People Management, Focusing on Customers, Data Collecting and Analysis, and Top Management and Leadership areas. There is a direct effect of CMMI implementation on software quality, where the effect appears through the implementation of Quality Management and Work Procedures and Processes areas. But there was no direct effect from the implementation of Strategic Management and Planning, People Management, Focusing on Customers, Data Collecting and Analysis, and Top Management and Leadership areas. There is, also, a direct effect of software quality on customer satisfaction. Whereas the higher the quality of the software, the higher effect on the increase of the satisfaction of the customers, and vice versa. Hence, software quality mediated the effect of CMMI implementation on the customer satisfaction. This indicates that there has to be an effect of the implementation of CMMI in Jordanian IT companies on the software quality in order to have a greater effect on the enhancement of the customer satisfaction.

An interesting finding of this study was that few of the surveyed companies were CMMI certified. Additionally, some companies were unaware that they were already implementing a considerable number of areas of CMMI. Few reasons can justify that, among which 1) high cost of implementing CMMI methodology as it requires contracting a certifying institute, and 2) top management focus on sales and market penetration especially that most IT companies in Jordan are mid-sized companies, and unaware of the Return on Investment (ROI) implications of implementing CMMI. 


\section{Conclusion}

In this paper, the effect of implementing CMMI in the Jordanian software firms has been quantitatively analyzed from four perspectives: The effect of CMMI implementation on customer satisfaction, the effect of CMMI implementation on software quality, the effect of software quality on customer satisfaction, and the effect of CMMI implementation on customer satisfaction through the software quality. The study has found that there is a direct effect of CMMI implementation on customer satisfaction, where the effect emerges through the implementation of Quality Management and Work Procedures and Processes areas. Moreover, it has found that there is a direct effect of CMMI implementation on software quality in which the effect appears through the implementation of Quality Management and Work Procedures and Processes areas. Regarding the effect of software quality and customer satisfaction, the study has found that the higher the quality of the software, the higher effect on the increase of the satisfaction of the customers, and vice versa. Additionally, it showed that software quality mediated the effect of CMMI implementation on the customer satisfaction. This indicates that there has to be an effect of the implementation of CMMI in IT Jordan companies on the software quality in order to have a greater effect on the enhancement of the customer satisfaction. The study encourages IT firms in Jordan applying the CMMI methodologies to enhance the satisfaction of their customers. They should focus on Quality Management, and Work Procedures and Processes. Moreover, IT companies should start to increase the awareness of CMMI approach and its benefits at their managerial level through improving employees understanding of the IT business, and not only on their technical knowledge; they also need to learn more about business management, latest studies and theories in running IT businesses successfully, skills on how to communicate with customers to understand their needs, and to start out contacting consultant and CMMI experts to propose to them how to start the first steps in getting CMMI certified.

\section{Appendix: Descriptive Statistics of CMMI Areas}

\begin{tabular}{|c|c|c|c|c|c|}
\hline Area & No. & Items & Mean & $\begin{array}{c}\text { Std. } \\
\text { Deviation }\end{array}$ & $\begin{array}{l}\text { Estimation } \\
\text { Degree }\end{array}$ \\
\hline \multirow{11}{*}{ 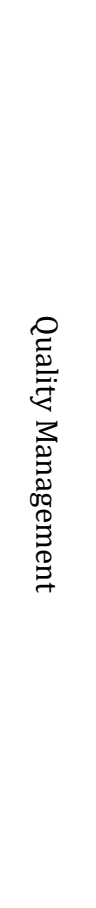 } & Q1 & Error rates are measured as a percentage of total output. & 3.20 & 0.97 & Average \\
\hline & Q2 & I am familiar with quality improvement processes in general. & 3.55 & 1.01 & High \\
\hline & Q3 & $\begin{array}{l}\text { Our organization uses quality control measures when } \\
\text { developing Information systems projects. }\end{array}$ & 3.60 & 0.98 & High \\
\hline & Q4 & $\begin{array}{l}\text { Our ultimate error rate goal is X errors/failures or fewer per one } \\
\text { million opportunities. }\end{array}$ & 3.05 & 1.02 & Average \\
\hline & Q5 & We are able to measure output quality accurately. & 3.22 & 1.13 & Average \\
\hline & Q6 & $\begin{array}{l}\text { Action plans used to define the accepted error rates are } \\
\text { effectively used by our software development functions. }\end{array}$ & 3.14 & 1.06 & Average \\
\hline & Q7 & $\begin{array}{l}\text { Our quality control procedures are effective within the } \\
\text { organization in continuously improving the quality of our } \\
\text { products/services. }\end{array}$ & 3.53 & 1.07 & High \\
\hline & Q8 & $\begin{array}{l}\text { Our quality control procedures are effective when applied to our } \\
\text { Information systems function in continuously improving our } \\
\text { Information systems. }\end{array}$ & 3.30 & 1.06 & Average \\
\hline & Q9 & $\begin{array}{l}\text { Our organization employs a particular quality control method } \\
\text { effectively. }\end{array}$ & 3.43 & 0.96 & High \\
\hline & Q10 & $\begin{array}{l}\text { We conduct testing procedures on our developed software } \\
\text { before implementation and used by the end-user. }\end{array}$ & 3.88 & 0.98 & High \\
\hline & Q11 & We define quality according to customer acceptance. & 3.43 & 0.99 & High \\
\hline
\end{tabular}




\begin{tabular}{|c|c|c|c|c|c|}
\hline Area & No. & Items & Mean & $\begin{array}{c}\text { Std. } \\
\text { Deviation }\end{array}$ & $\begin{array}{l}\text { Estimation } \\
\text { Degree }\end{array}$ \\
\hline & Q12 & $\begin{array}{l}\text { We use Information System to analyze customer satisfaction } \\
\text { rates with our products and/or services. }\end{array}$ & 3.15 & 1.13 & Average \\
\hline & Q13 & $\begin{array}{l}\text { We are familiar with the Capability Maturity Model Integration } \\
\text { (CMMI) process for use in software development. }\end{array}$ & 2.89 & 1.20 & Average \\
\hline & Q14 & $\begin{array}{l}\text { We use cross-functional teams to suggest and make } \\
\text { improvements throughout the organization. }\end{array}$ & 3.49 & 0.98 & High \\
\hline & & Quality Management Mean & 3.34 & 0.73 & Average \\
\hline \multirow{12}{*}{ 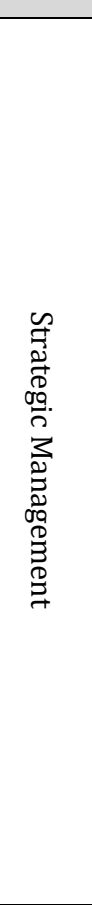 } & Q15 & Our organization is continually looking to improve quality. & 3.91 & 0.95 & High \\
\hline & Q16 & $\begin{array}{l}\text { Our communication between the strategic planning committee } \\
\text { and Information systems project management is good. }\end{array}$ & 3.41 & 1.00 & High \\
\hline & Q17 & $\begin{array}{l}\text { We continually search for ways to cut down on production } \\
\text { errors. }\end{array}$ & 3.81 & 0.93 & High \\
\hline & Q18 & $\begin{array}{l}\text { We, as an organization, take a pro-active approach to problem } \\
\text { solving - we act to prevent problems before they happen. }\end{array}$ & 3.63 & 0.91 & High \\
\hline & Q19 & $\begin{array}{l}\text { Our top management understands the value of Information } \\
\text { System and is committed to it. }\end{array}$ & 3.66 & 0.91 & High \\
\hline & Q20 & $\begin{array}{l}\text { Once a process is improved we continually check it to maintain } \\
\text { an acceptable level of failure. }\end{array}$ & 3.55 & 0.94 & High \\
\hline & Q21 & $\begin{array}{l}\text { We identify acceptable error rates prior to measurement of } \\
\text { processes specialized in software development }\end{array}$ & 3.22 & 1.05 & Average \\
\hline & Q22 & Everyone is aware of our accepted error rate. & 2.85 & 0.99 & Average \\
\hline & Q23 & Everyone works toward not exceeding the accepted error rates & 3.35 & 0.93 & Average \\
\hline & Q24 & We actively manage our supplier relationships. & 3.57 & 0.88 & High \\
\hline & Q25 & We continuously improve our processes and work procedures & 3.66 & 0.92 & High \\
\hline & Q26 & $\begin{array}{l}\text { Everyone is aware of an action plan that is used to help on not } \\
\text { exceeding the accepted rates of errors }\end{array}$ & 3.35 & 0.97 & Average \\
\hline \multirow{12}{*}{ 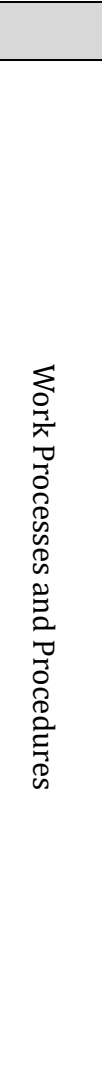 } & & Strategic Management Mean & 3.49 & 0.67 & High \\
\hline & Q27 & $\begin{array}{l}\text { Our organization defines an acceptable error rates on the work } \\
\text { processes and procedures before they are put on use }\end{array}$ & 3.24 & 0.94 & Average \\
\hline & Q28 & $\begin{array}{l}\text { We employ processes to identify and correct problems as they } \\
\text { occur. }\end{array}$ & 3.24 & 1.06 & Average \\
\hline & Q29 & $\begin{array}{l}\text { We measure process failures in an attempt to identify the } \\
\text { precise location of a failure. }\end{array}$ & 3.43 & 0.95 & High \\
\hline & Q30 & We take measures to correct failed processes immediately. & 3.51 & 1.14 & High \\
\hline & Q31 & $\begin{array}{l}\text { We employ planning and development meetings which involve } \\
\text { representatives from all stakeholder groups in Information } \\
\text { System projects; i.e. strategic planning committee, Information } \\
\text { System management, end-users, Information System } \\
\text { development, etc. }\end{array}$ & 3.18 & 1.09 & Average \\
\hline & Q32 & $\begin{array}{l}\text { We use past experience to overcome present problems in } \\
\text { Information System }\end{array}$ & 3.63 & 1.01 & High \\
\hline & Q33 & We measure end-user acceptance of Information System. & 3.61 & 0.92 & High \\
\hline & Q34 & $\begin{array}{l}\text { Location of Information System problems is identified using } \\
\text { measurement and analysis techniques. }\end{array}$ & 3.25 & 1.02 & Average \\
\hline & Q35 & $\begin{array}{l}\text { We use the Capability Maturity Model Integration in our } \\
\text { software development. }\end{array}$ & 2.96 & 1.21 & Average \\
\hline & Q36 & $\begin{array}{l}\text { There are action plans that are used to help on not exceeding the } \\
\text { accepted rates of errors }\end{array}$ & 3.13 & 0.97 & Average \\
\hline & Q37 & $\begin{array}{l}\text { There are action plans that are used to help on not exceeding the } \\
\text { accepted rates of errors when developing our software }\end{array}$ & 3.05 & 1.10 & Average \\
\hline
\end{tabular}




\begin{tabular}{|c|c|c|c|c|c|}
\hline Area & No. & Items & Mean & $\begin{array}{c}\text { Std. } \\
\text { Deviation }\end{array}$ & \begin{tabular}{|c|} 
Estimation \\
Degree
\end{tabular} \\
\hline \multicolumn{3}{|r|}{ Work Processes and Procedures Mean } & 3.29 & 0.81 & Average \\
\hline \multirow{3}{*}{ 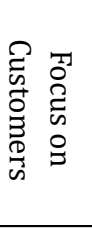 } & Q38 & $\begin{array}{l}\text { We take into account the external requirements of the } \\
\text { organization when planning Information System (i.e. customers, } \\
\text { competition, environmental concerns, etc.). }\end{array}$ & 3.59 & 0.91 & High \\
\hline & Q39 & We include customers when we measure our error rates. & 3.30 & 1.02 & Average \\
\hline & Q40 & We continuously measure the satisfaction of our customers & 3.72 & 0.89 & High \\
\hline \multicolumn{3}{|r|}{ Focus on Customers Mean } & 3.53 & 0.78 & High \\
\hline \multirow{4}{*}{ 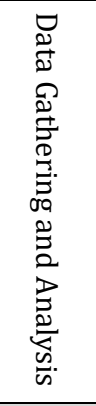 } & Q41 & $\begin{array}{l}\text { Measurement results are used to make improvements in } \\
\text { Information System processes, procedures, training, security, } \\
\text { usage, response times, etc. }\end{array}$ & 3.38 & 1.05 & Average \\
\hline & Q42 & $\begin{array}{l}\text { We collect data in order to check if processes are operating } \\
\text { within clearly defined parameters. }\end{array}$ & 3.36 & 1.02 & Average \\
\hline & Q43 & $\begin{array}{l}\text { We use information systems that provide us with accurate } \\
\text { information that helps in benchmarking and evaluate the } \\
\text { competition in the market }\end{array}$ & 3.20 & 1.08 & Average \\
\hline & Q44 & The information we deal with are up-to-date & 3.49 & 0.99 & High \\
\hline \multicolumn{3}{|r|}{ Data Gathering and Analysis Mean } & 3.35 & 0.86 & Average \\
\hline \multirow{4}{*}{$\begin{array}{c}0 \\
0 \\
0 \\
0 \\
0 \\
0 \\
3 \\
0 \\
0 \\
0 \\
00 \\
0 \\
0 \\
0 \\
0 \\
0\end{array}$} & Q45 & We are continuously training our employees. & 3.36 & 1.02 & Average \\
\hline & Q46 & $\begin{array}{l}\text { We do a good job of communicating our desire to continually } \\
\text { improve all processes. }\end{array}$ & 3.61 & 0.90 & High \\
\hline & Q47 & We continuously measure the job satisfaction of our employees & 3.27 & 0.99 & Average \\
\hline & Q48 & $\begin{array}{l}\text { We take care of the quality of the work environment in our } \\
\text { organization }\end{array}$ & 3.55 & 0.91 & High \\
\hline \multicolumn{3}{|r|}{ People Management Mean } & 3.44 & 0.81 & High \\
\hline \multirow{3}{*}{ 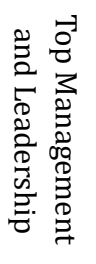 } & Q49 & $\begin{array}{l}\text { Top management shares their vision and mission with other } \\
\text { employees in the organization }\end{array}$ & 3.53 & 0.99 & High \\
\hline & Q50 & Top management supports the employees in job development & 3.64 & 0.84 & High \\
\hline & Q51 & $\begin{array}{l}\text { Top management gives the opportunity to the employees on } \\
\text { setting the strategic plans }\end{array}$ & 3.34 & 1.05 & Average \\
\hline \multicolumn{3}{|r|}{ Top Management and Leadership Mean } & 3.50 & 0.80 & High \\
\hline \multirow{12}{*}{ 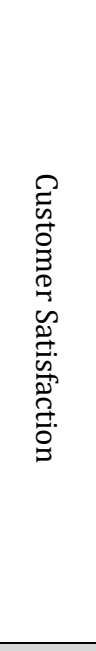 } & Q52 & Does the system provide the precise information you need? & 3.63 & 0.92 & High \\
\hline & Q53 & Does the information content meet your needs? & 3.64 & 0.85 & High \\
\hline & Q54 & $\begin{array}{l}\text { Does the system provide reports that seem to be just about } \\
\text { exactly what you need? }\end{array}$ & 3.47 & 0.91 & High \\
\hline & Q55 & Does the system provide sufficient information? & 3.51 & 0.89 & High \\
\hline & Q56 & Is the system accurate? & 3.59 & 0.86 & High \\
\hline & Q57 & Are you satisfied with the accuracy of the system? & 3.38 & 0.91 & Average \\
\hline & Q58 & Do you think the output is presented in a useful format? & 3.41 & 1.05 & High \\
\hline & Q59 & Is the information clear? & 3.55 & 0.91 & High \\
\hline & Q60 & Is the system user friendly? & 3.45 & 0.93 & High \\
\hline & Q61 & Is the system easy to use? & 3.59 & 0.95 & High \\
\hline & Q62 & Do you get the information you need in time? & 3.57 & 0.96 & High \\
\hline & Q63 & Does the system provide up-to-date information? & 3.57 & 1.00 & High \\
\hline \multicolumn{3}{|r|}{ Customer Satisfaction Mean } & 3.52 & 0.75 & High \\
\hline
\end{tabular}

\section{References}


[1] Buenen, M., \& Muthukrishnan, G. (2016). World Quality Report 2016-17. Technical report, Capgemini, Sogeti and HPE.

[2] Standish Group. (1995). Chaos - The state of the software industry. Standish Group International, Technical Report, 1-11.

[3] Butler, K., (1995). The economics benefits of software process improvement. CrossTalk (July), 14-17.

[4] Yamamura, G. (1999). Software process satisfied employees. IEEE Software, 83-85.

[5] Staples, M., Niazi, M., Jeffery, R., Abrahams, A., Byatt, P., \& Murphy, R. (2007). An exploratory study of why organizations do not adopt CMMI. J. Syst. \& Softw. 80(6), 883-895.

[6] Vasconcellos, F. J., Landre, G. B., Cunha, J. A. O., Oliveira, J. L., Ferreira, R. A., \& Vincenzi, A. M. (2017). Approaches to strategic alignment of software process improvement: A systematic literature review. Journal of Systems and Software, 123, 45-63.

[7] Mejia, J., Muñoz, E., \& Muñoz, M. (2016). Reinforcing the applicability of multi-model environments for software process improvement using knowledge management. Science of Computer Programming, 121, 3-15.

[8] Lee, J. C., Shiue, Y. C., \& Chen, C. Y. (2016). Examining the impacts of organizational culture and top management support of knowledge sharing on the success of software process improvement. Computers in Human Behavior, 54, 462-474.

[9] Chevers, D. A., \& Grant, G. (2016). Software process improvement adoption and benefits in canadian and English - speaking caribbean software development firms. The Electronic Journal of Information Systems in Developing Countries, 77(1), 1-15.

[10] Kishore, R., Swinarski, M. E., Jackson, E., \& Rao, H. R. (2012). A quality-distinction model of IT capabilities: conceptualization and two-stage empirical validation using CMMi processes. IEEE Transactions on Engineering Management, 59(3), 457-469.

[11] Chrissis, M., Konrad, M., \& Shrum, S. (2003). CMMI guidelines for process integration and product improvement. 1st Edition Addison-Wesley Professional, Boston, USA.

[12] Chaudhary, M., \& Chopra, A. (2017). CMMI for Development. Berkeley: Apress.

[13] Silva, F. S., Soares, F. S., Peres, A. L., Azevedo, I. M., Vasconcelos, A. P. L., Kamei, F. K., \& Lemos, M. S. R. (2015). Using CMMI together with agile software development: A systematic review. Information and Software Technology, 58, 20-43.

[14] Mishra, K. D. (2016). Software quality management - An overview of CMMI and TPI quality assessment procedures. Adhyayan, 45.

[15] Olaimat, M., \& Rashed, A. A. (2007). Software industry in Jordan the prospects and hopes. Zaytounah University, Amman, Jordan.

[16] Al-Allaf, O. N. (2012). The usage of capability maturity model integration and web engineering practices in large web development enterprises: An empirical study in Jordan. Journal of Theoretical and Applied Information Technology, 39(2), 150-166.

[17] Cheng, C, Chang, J., \& Kuo, C. (2011) A CMMI appraisal support system based on a fuzzy. Quantitative Benchmarks Model. Expert Syst. Appl, 38(4), 4550-4558.

[18] Sun, Y., \& Liu, X. (.2010). Business-oriented software process improvement based on CMMI using QFD. Information and Software Technology, 52, 79-91.

[19] Pane, E. S., \& Sarno, R. (2015). Capability maturity model integration (CMMI) for optimizing objectoriented analysis and design (OOAD). Procedia Computer Science, 72, 40-48.

[20] Örgün, P., Güngör, D., Kuru, Y. Y., Metin, Ö. O., \& Yllmaz, M. (2018, September). Software development overall efficiency improvement in a CMMI level 5 organization within the scope of a case study. Proceedings of the 2018 3rd International Conference on Computer Science and Engineering (UBMK) (pp. 
258-263).

[21] Riera, J., (2011) Process mining opportunities for CMMI assessments. Department of Technology Management, Universitat Politècnica de Catalunya, Spain.

[22] Proença, D., \& Borbinha, J. (2016). Maturity models for information systems-a state of the art. Procedia Computer Science, 100, 1042-1049.

[23] Shetty, A. (2006). An approach to defining a level 3 CMMI engineering process for mission and safety critical (MASC) systems. University of Houston, USA.

[24] Dymond, K. M. (2007). A guide to the CMMI: Interpreting the capability maturity model.

[25] Beadle, B. (2009) CMMI as contemporary iron cage: A grounded analysis from the perspective of practicing engineers in defense engineering. The University of St. Thomas, USA.

[26] Tully, E. (2007) A guide for utilizing six sigma in achieving CMMI maturity goals. California State University, USA.

[27] Norman, G. (2007) A grounded theory of software process improvement model adoption. College of Human Resources and Education, USA.

[28] Erukulapati, K. (2011) Improving quality of services using CMMI for services. California State University, USA.

[29] Subramanian, G., Jiang, J., \& Klein, G. (2007). Software quality and IS project performance improvements from software development process maturity and IS implementation strategies. Journal of Systems and Software, 80(4), 616-627.

[30] Geddes, D. (2007). Quality management intensity during Is development: Does it influence end-user satisfaction? Department of Management, Southern Illinois University Carbondale, Illinois. USA.

[31] Shahriari, M., Pilevari, N., \& Haghight, M. (2016). Organizational maturity assessment in the field of information technology management using CMMI model. International Journal of Humanities and Cultural Studies (IJHCS) ISSN 2356-5926, 221-233.

[32] Wallshein, C. C., \& Loerch, A. G. (2015). Software cost estimating for CMMI level 5 developers. Journal of Systems and Software, 105, 72-78.

[33] Silva, F. S., Soares, F. S. F., Peres, A. L., Azevedo, I. M., Vasconcelos, A. P. L., Kamei, F. K., \& Lemos, M. S. R. (2015). Using CMMI together with agile software development: A systematic review. Information and Software Technology, 58, 20-43.

[34] Abdel-Hamid, A. N., \& Hamouda, A. E. D. (2015). Lean CMMI: An iterative and incremental approach to CMMI-based process improvement. Agile Conference.

[35] Choetkiertikul, M., Dam, H. K., Ghose, A., \& Sunetnanta, T. T. (2014). A CMMI-based automated risk assessment framework. Proceedings of the 2014 21st Asia-Pacific Software Engineering Conference (pp. 63-68).

[36] Nilsson, L., Michael, D., Johnson, G. A. (2001). The impact of quality practices on customer satisfaction and business results: Product versus service organizations. Journal of Quality Management, 6(1), 5-27.

[37] Preuninger, R. (2006). The advantages of implementing software engineering process models. The University of Texas, USA.

[38] Saeed, A., Usmani, R. S. A., Akram, H., Saqlain, S. M., \& Ghani, A. (2017). The impact of capability maturity model integration on return on investment in IT industry. Engineering, Technology and Applied Science Research, 7(6), 2189-2193.

[39] Goldenson, D., \& Gibson, D. (2003), Demonstrating the impact and benefits of CMMI: An update and preliminary results software engineering institute. Carnegie Mellon.

[40] Parzinger, M., \& Nath, R., (2000) A study of the relationships between total quality management implementation factors and software quality. Total Quality Management, 11(3), 353- 371. 
[41] Titov, S., Bubnov, G., Guseva, M., Lyalin, A., \& Brikoshina, I. (2016). Capability maturity models in engineering companies: case study analysis. Proceedings of the ITM Web of Conferences.

[42] Amer, S. K., Badr, N., Ibrahim, O., \& Hamad, A. (2017). Empirical study on the effectiveness of adopting software quality frameworks in the Egyptian software industry. Proceedings of the 2017 Eighth International Conference on Intelligent Computing and Information Systems.

[43] Lukasiewicz, K., \& Miler, J. (2012). Improving agility and discipline of software development with the scrum and CMMI. IET Software, 6(5), 416-422.

[44] Dalton, J. (2016). A guide to scrum and CMMI: Improving agile performance with CMMI. CMMI Institute, 1-130.

[45] Engdashet, T., Machado, R. J., \& Midekso, D. (2016). Integrated framework of agile and CMMI: An alternative path towards product focused SPI for small companies. Lecture Notes on Software Engineering, 4(1), 1.

[46] Al-Salim, M., \& Al-Alawneh A. (2005). TQM in the Jordanian software companies: A field study SCIENTific. Journal of Administrative Development, 3(5), 21-39.

[47] Samman, S. I. (2003). Integrated total quality management / business process re-engineering model. University of Jordan, Jordan.

[48] Samman, S. I. (2004). Integrated total quality management, University of Jordan, Jordan.

[49] Settleourre, J. (2008). Process development using the capability maturity model integration (CMMI). California State University Dominguez Hills, USA.

[50] Platt, M. (2005). Choosing the best quality tool for a non-manufacturing environment, CMMI, Or Six Sigma? California State University Dominguez Hills, USA.

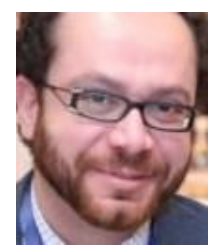

1.3 .

Mohammad Abu Baker is a Quality Assurance Manager, and has around 15 years of experience working in the ICT sector in Jordan, specialized in QC and QA field. He received his BSc degree in Computer Science from Al Al-Bayt University, Jordan, followed by MSc. in Business Administration from Al Balqaa Applied University, Jordan in 2012. He is specialized in the implementation of different Quality Assurance methodologies in different Software houses in Jordan, mainly CMMI-DEV Level 3 Version

Mohammad Khair Aleem Abu-Zaid is a professor at Al-Balqa' Applied University (BAU). He received his B.S. in business management from University of Jordan, He received his M.S. in business management from the University of Jordan in 1999. In 2006, he received his Ph.D. in management from Amman Arab University.

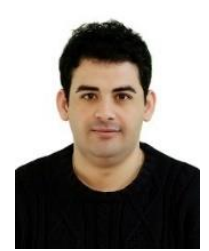

Hamad Iqab Alsawalqah received his B.S. in computer information systems from University of Jordan, Jordan, in spring 2004. He received his M.A in management information systems from Amman Arab University for Graduate Studies, Jordan, in spring 2006. In summer 2008, he received his second M.A in software engineering from Korea Advanced Institute of Science and Technology (KAIST). From August 2006, he was a member of the Global IT Technology program at KAIST until August 2008. He received his Ph.D. in information and communications engineering, software engineering, from KAIST in 2014. His research interests are in software product lines, product management, project management, and bug prediction.

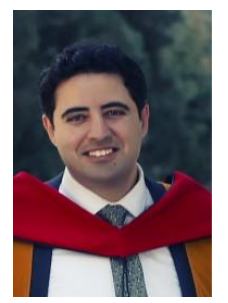

Yazan Alshamaileh is an assistant professor at King Abdullah II School for Information Technology, University of Jordan. He received his BSc degree computer information systems from Mu'tah University, Jordan, followed by a MSc. in business information Technology from Northumbria University, England. In 2013, he has been awarded his Ph.D. Degree in e-business from University of Newcastle, UK. He specializes in Cloud Computing, and consumer behavior, as well as Information and Communication Technology innovation adoption in the Small and Medium-sized Enterprises. 
Bashar A. Al-Shboul is an assistant professor at University of Jordan, Jordan. He received his B.S. in information technology from Al-Balqa'a Applied University, Jordan. He received his M.S. in computer Science from the University of Jordan in 2006. In 2012, he received his Ph.D. in information \& telecommunications technology from Korea Advanced Institute of Science and Technology. His research interests include query expansion, legal document analysis, topic mining, social media analysis, trend detection, and syntactic \& semantic plagiarism detection. 